\title{
Cytological Studies in the Iridaceae
}

\section{Edgar Gwynn}

Department of Biology, Washington College, Chestertown, Maryland, U.S.A.

Received October 27,1957

The Iridaceae are a widespread family of the warm and temperate regions of the world. There are approximately sixty genera and one thousand species according to Swingle (1946), many of which are or have been cultivated. Despite their cosmopolitan nature, great numbers and extensive use as ornamentals, apparently less than four hundred species have been investigated cytologically. Most of those that have been analyzed are in the large, cultivated genera such as Crocus, Gladiolus and Iris. The present work deals with several South African genera and species apparently unreported hitherto.

\section{Material and methods}

All chromosome counts reported in the present work were obtained from the root tips of germinating seeds. The seeds were supplied by the National Botanic Gardens, Kirstenbosch, Newlands, Cape Province, South Africa. This organization also furnished the generic and specific names in each instance.

Before germination, the seeds were soaked, sterilized with mercuric chloride, washed in sterile water and plated out in sterile petri dishes. After some difficulty with germination sufficient root tips were obtained for cytological purposes. The material was fixed in Randolph's modified Navashin fluid for 20-24 hours. Following this treatment the material was embedded in paraffin and cut in serial sections at a thickness of 14 microns. The sections were stained with methyl violet-erythrosin following the schedule of Johansen (1940). These procedures give excellent fixation and very clearly stained chromosomes. Camera lucida drawings were made at a magnification of $1800 \times$.

\section{Reults}

Babiana erectifolia $2 n=14$ (Figs. 1, 2). The fourteen chromosomes of this species may be divided into three groups on the basis of size. Four are quite long and stand out clearly because of their relatively great size. The ten remaining chromosomes may be further divided into six short ones and four slightly longer ones. Size differences in the group of ten chromosomes are not great.

Babiana tubiflora $2 n=14$ (Fig. 3). There is a readily apparent simi- 
larity between the chromosomes in this species and those of $B$. erectifolia. Four are very long. There are six short ones and four slightly longer chromosomes.

Geissorhiza secunda $2 n=26$ (Fig. 8). The twenty six chromosomes are rather uniform in size and shape. It has proven impossible to separate them into groups on the basis of size.

Romulea latifolia $2 n=27$ (Fig. 7). The chromosomes may be divided into three groups. There are six long, six short and fifteen intermediate in size. The difference in length is not as marked as it is in Babiana. One chromosome in the group of six short ones is quite small and may be fragmentary in nature. It was apparently not cut in the preparation of the sections.
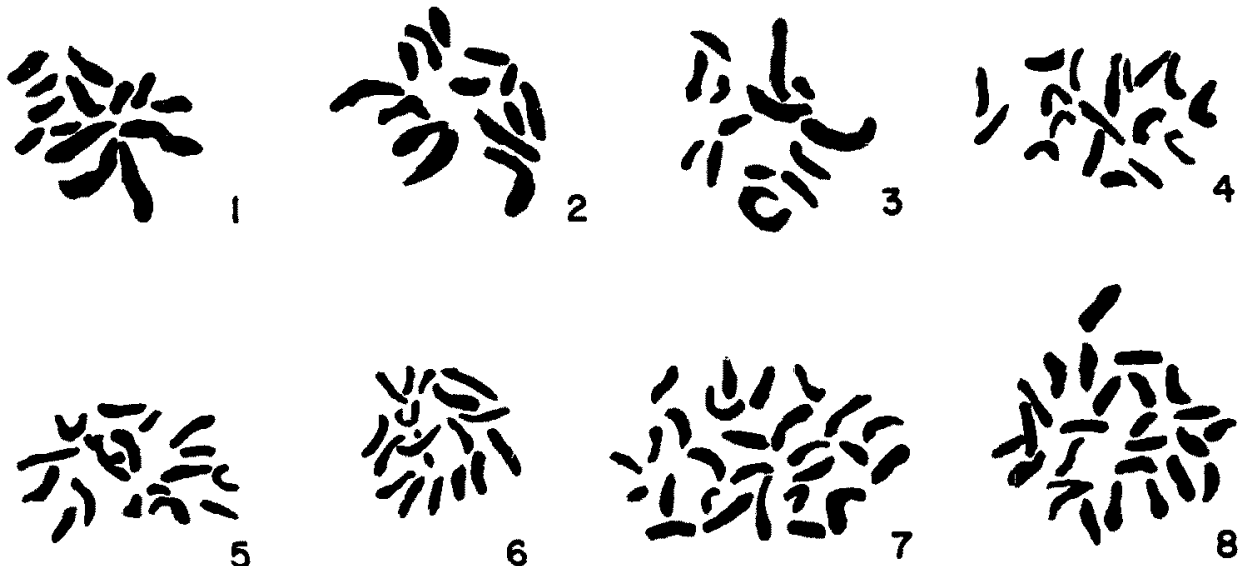

Figs 1-8. 1, Babiana erectifolia $2 n=14.2$, Babiana erectifolia $2 n=14.3$, Babiana tubiftora $2 n=14 . \quad 4$, Romulea rosea $2 n=18 . \quad 5$, Romulea rosea $2 n=18.6$, Romulea ochroleuca $2 n=18.7$, Romilea latifolia $2 n=27$. 8, Geissorhiza secunda $2 n=26$.

Romulea ochroleuca $2 n=18$ (Fig. 6). There are four long, two short and twelve intermediate chromosomes. The size differences are not very great in any instance.

Romulea rosea $2 n=18$ (Figs 4,5 ). Of the eighteen chromosomes in this species, two are long, 10 are slightly shorter and the remaining six are short and plump. Size differences are readily apparent only between the largest and smallest.

Romulea bulbocodioides $2 n=$ c. 18. The material available for this species has proven to be unsatisfactory for accurate analysis. There are apparently eighteen chromosomes but the exact number and the size groups cannot be distinguished with certainty.

\section{Discussion}

There can be little doubt, as far as the material herein reported is concerned, that the $2 n$ number of both Babiana erectifolia and B. tubiflora 
is 14. The plates are quite clear and the similarity of the chromosomes is marker. On the basis of this material, the basic number for the genus is seven. However, Brittingham (1934) has reported for Babiana stricta that $2 n=12$. He states that Yamamoto also reports $2 n=12$. In describing the chromosomes the former author states that "four are very long, four about a third as long, and four are quite short and plump". This agrees very well with the size relationships recorded for the genus in the present paper except that there are two short chromosomes in addition noted here.

On the basis of the three species now reported it is not possible to state definitely the basic number of the genus Babiana. The tentative number may be given as 6 or 7 . It appears too early to attempt this when one considers that Thiselton-Dyer (1897) lists twenty six species in the genus in South Africa. It is quite possible that more than one basic number may be found as was the case in Crocus and Iris.

The chromosome number reported for Geissorhiza secunda, where $2 n$ has been found to be twenty six, is apparently the first report for this genus. On this flimsy evidence the basic number indicated is thirteen. ThiseltonDyer reports twenty nine species in South Africa.

In the genus Romulea five species now have been reported, including one with the chromosome number listed as tentatively established. Romulea ochroleuca and $R$. rosea have been found to have a $2 n$ number of eighteen in the present work. $R$. bulbocodioides is tentatively reported to have a $2 n$ number of about eighteen. From this evidence the basic number for the genus is apparently nine. Romulea latifolia is reported in the present paper to have a $2 n$ number of 27 . This species appears to be triploid in nature. The single small chromosome or, possibly, fragment needs further study before its role can be established.

There is only one previous cytological report in the genus Romulea which has come to the writer's attension. Matsuura and Suto in Darlington and Janaki-Ammal (1945) have reported the $2 n$ number of Romulea parviflora to be about sixty. This number is assigned as an approximation by the researchers. Darlington assigns a tentative basic number of fifteen to the genus on the basis of this work. It seems probable in the light of the evidence presented here that $R$. parviflora is hexaploid in nature with $6 x=54$ or heptaploid with $7 x=63$. This is assuming that nine is the basic number and that the tentative sixty allows for so great a departure. The possibility that Romulea is a polybasic genus cannot be ruled out on the basic of the present meager evidence. Thiselton-Dyer lists about fifty species in Africa and Europe.

\section{Summary}

Chromosome counts and descriptions are given for some species of the genera Babiana, Geissorhiza and Romulea in the Iridaceae. On the basis 
of three species of Babiana reported here and elsewhere, the basic number for the genus may be tentatively set at 6 or 7 . From five species of Romulea so far reported, the basic number of the genus may be set at 9 . A possible triploid species is reported. One species in the genus Geissorhiza reported here has a basic number of 13. Many other species of these genera and others in the Iridaceae remain to be investigated cytologically.

\section{Literature cithd}

Brittingham, W. H. 1934. Cytological studies on some genera of the Iridaceae. Amer. Jour. Bot. 21: 77-84

Darlington, C. D. and Janaki-Armal, E. K. 1954. Chromoscre atlas of cultivated plants. London: George Allen and Unwin Ltd.

Johansen, D. A. 1940. Plant microtechnique. New York: McGraw.Hill Book Co.

Swingle, D. B. 1946. A textbook of Systematic Botany, New York: McGraw-Hill Book Co. Thiselton-Dyer, W. T. 1897. Flore Capensis. vol. vi. Covent Garden: L. Reeve and Co. 